\title{
Advanced dental disease in people with severe mental illness: systematic review and meta-analysis
}

Steve Kisely, Lake-Hui Quek, Joanne Pais, Ratilal Lalloo, Newell W. Johnson and David Lawrence

\section{Background}

Psychiatric patients have increased comorbid physical illness. There is less information concerning dental disease in this population in spite of risk factors including diet and psychotropic side-effects (such as xerostomia).

\section{Aims}

To compare the oral health of people with severe mental illness with that of the general population.

\section{Method}

A systematic search for studies from the past 20 years was conducted using Medline, PsycINFO, Embase and article bibliographies. Papers were independently assessed. The primary outcome was total tooth loss (edentulousness), the end-stage of both untreated caries and periodontal disease. We also assessed dental decay through standardised measures: the mean number of decayed, missing and filled teeth (DMFT) or surfaces (DMFS). For studies lacking a control group we used controls of similar ages from a community survey within 10 years of the study.

\section{Results}

We identified 21 papers of which 14 had sufficient data $(n=2784$ psychiatric patients) and suitable controls $(n=31084)$ for a random effects meta-analysis. People with severe mental illness had 3.4 times the odds of having lost all their teeth than the general community $(95 \% \mathrm{Cl} 1.6-7.2)$. They also had significantly higher scores for DMFT (mean difference $6.2,95 \% \mathrm{Cl} 0.6-11.8$ ) and DMFS (mean difference $14.6,95 \% \mathrm{Cl}$ 4.1-25.1). Fluoridated water reduced the gap in oral health between psychiatric patients and the general population.

\section{Conclusions}

Psychiatric patients have not shared in the improving oral health of the general population. Management should include oral health assessment using standard checklists that can be completed by non-dental personnel. Interventions include oral hygiene and management of xerostomia.

\section{Declaration of interest}

None.

indicator of both dental caries and periodontal disease in people with severe mental illness. To our knowledge, this is the first systematic review and meta-analysis of this topic in people with severe mental illness. We also considered the effect of water fluoride levels on differences in oral health between people with and without severe mental illness. Our aim, therefore, was to compare the prevalence of edentulousness in people with severe mental illness with that in the general population. We also compared levels of dental decay. We did this by a systematic review and meta-analysis of studies from the past 20 years.

\section{Method} and dentine) from a build-up of dental plaque which microorganisms colonise. If plaque is not removed, and there is frequent intake of readily fermentable carbohydrates in the diet, irreversible cavitation can occur. This will normally require restoration or extraction of the tooth if the dental pulp has become infected. ${ }^{13}$ Periodontal disease usually begins with gingivitis - inflammation of the gingival tissues (gums). This, too, is caused by longstanding accumulation of dental plaque in contact with the soft tissues. In patients who harbour particularly pathogenic microflora, or whose host response to these micro-organisms is ineffective, inflammation spreads to the periodontal ligament with destruction of connective tissues and surrounding (alveolar) bone. Signs of periodontal disease include bleeding gums and pockets where the gingivae have become detached from the teeth. In more advanced disease there is exposure of tooth roots and mobility of teeth. ${ }^{14}$ These symptoms and signs are often associated with halitosis (bad breath).

The end-stage of both untreated dental caries and periodontal disease is tooth loss, which can involve the whole dentition (edentulousness). ${ }^{15}$ We therefore focused on this condition as an

\section{Oral health outcomes}

The primary outcome of this study was edentulousness, usually expressed as a dichotomous variable. We also assessed the number of decayed, missing and filled dental surfaces or teeth; both these indices are expressed as a continuous variable. The number of decayed, missing and filled teeth reflects a person's lifetime experience of dental caries. ${ }^{16}$ This is because both dental decay and its treatment leave permanent marks, either through the presence of fillings or the loss of affected teeth by extraction. The total number of teeth (T) and surfaces $(\mathrm{S})$ that are decayed (D), missing because of pathology (M) or filled (F) are measures referred to as DMFT and DMFS respectively. In both, an increase in score means greater dental decay. Scores for DMFT and DMFS vary widely by country, from mean DMFT scores of under 5 in India to 12.8 in the most recent community survey in a highincome country (Australia). ${ }^{16-18}$ Scores for DMFS are higher than for DMFT as the former counts damage to each surface of each tooth rather than counting the tooth as a single unit; anterior 
teeth have four surfaces and posterior teeth five. In interpreting both, it is useful to recall that humans have 32 permanent teeth. The maximum possible DMFT score is therefore 32, whereas the maximum DMFS is 148 .

\section{Inclusion and exclusion criteria}

We included studies with a focus on severe mental illness, defined as a primary diagnosis of dementia, schizophrenia, bipolar affective disorder or other affective disorder. We included studies using clinical diagnoses or diagnostic criteria. We excluded studies of eating disorder and of post-traumatic stress disorder in veterans, as these are very different patient groups. We also excluded studies of people with primary alcohol or substance use disorders and people with intellectual disability for the same reason. Finally, our focus was on edentulousness as the end-stage of the two main dental diseases. We therefore excluded studies of less severe dental outcomes such as poor oral hygiene.

\section{Search strategy}

We searched Medline, PsycINFO and Embase for the period January 1988 until March 2010 using the following text, MeSH or Emtree terms as appropriate: mental illness, mental disorders, dementia, psychosis, psychotic disorders, depression, depressive disorders, bipolar disorder, mood disorder, schizophrenia, oral health, dentistry and dental care. We searched for further publications by scrutinising the reference lists of initial studies identified and other relevant review papers. We also contacted selected authors and experts. Two reviewers (S.K. and L.H.Q.) independently assessed abstracts, and a third (J.P.) checked the extracted data for accuracy.

For inclusion in the meta-analysis, studies had to have suitable controls. Where these were not included we looked for controls from a survey of a similar community and age group, conducted within 10 years of the index study. This is because oral health varies between populations, by both age and over time: for example, oral health has improved considerably over the past 20 years in most high-income countries. ${ }^{19-21}$ We also ensured that the comparison data came from areas with similar levels of fluoride in the water supply. We determined water fluoride levels from the paper itself where this was given, or from published reviews of fluoridation by region and country. ${ }^{22-24}$

\section{Statistical analysis}

We used Review Manager version 5.0 for Windows, a statistical software package for analysing a Cochrane Collaboration systematic review, for our analysis. We calculated odds ratios for edentulousness, given that the studies we included had a crosssectional design. We calculated the mean differences for continuous data as studies used the same scale for each outcome (DMFT, DMFS). We assessed heterogeneity using the $I^{2}$ statistic. This provides an estimate of the percentage of variability due to heterogeneity rather than chance alone. An $I^{2}$ estimate of $50 \%$ or greater indicates possible heterogeneity, and scores of $75-100 \%$ indicate considerable heterogeneity. ${ }^{25}$ The $I^{2}$ statistic is calculated using the chi-squared statistic $(Q)$ and its degrees of freedom. It has several advantages over the $Q$ statistic alone in that it does not depend on the number of studies in the meta-analysis and so has greater power to detect heterogeneity when the number of studies is small. ${ }^{26}$ The $I^{2}$ statistic can also be interpreted similarly irrespective of whether outcome data are dichotomous or continuous.

We used a random effects model throughout as we found significant heterogeneity in the majority of our analyses. This model assumes that variations in effect among different studies are due to differences in samples or paradigms and have a normal distribution, i.e. that heterogeneity exists. In addition, where possible, we investigated heterogeneity by analysing data both with and without outlying studies as part of a sensitivity analysis. Where information concerning the presence or absence of fluoridation of public water supplies was available, we also undertook sensitivity analyses as to whether this mitigated any increased risk of dental disease in psychiatric patients. Fluoridation aims to achieve around 1 part of fluoride for every million parts of water. ${ }^{23,24}$ Where there were sufficient studies, we also undertook sensitivity analyses of the effect of including only studies that used international diagnostic criteria such as the ICD or DSM.

We tested for publication bias in two ways, using the fail-safe $N$ statistic and funnel plot asymmetry. The fail-safe $N$ is the number of non-significant studies that would be necessary to reduce the odds ratio or effect size to a negligible value. In tests for a skewed funnel plot, low $P$-values suggest publication bias.

\section{Results}

We found over 550 citations of interest in the initial electronic searches, of which 38 papers were potentially relevant and assessed for eligibility. We were unable to obtain the full text of one potentially relevant paper which we had identified from its abstract. Of the remainder, we excluded 17 which did not meet our inclusion criteria, leaving 21 papers for formal review (Fig. 1). ${ }^{1,11,12,17,27-43}$ Online Table DS1 gives details of these 21

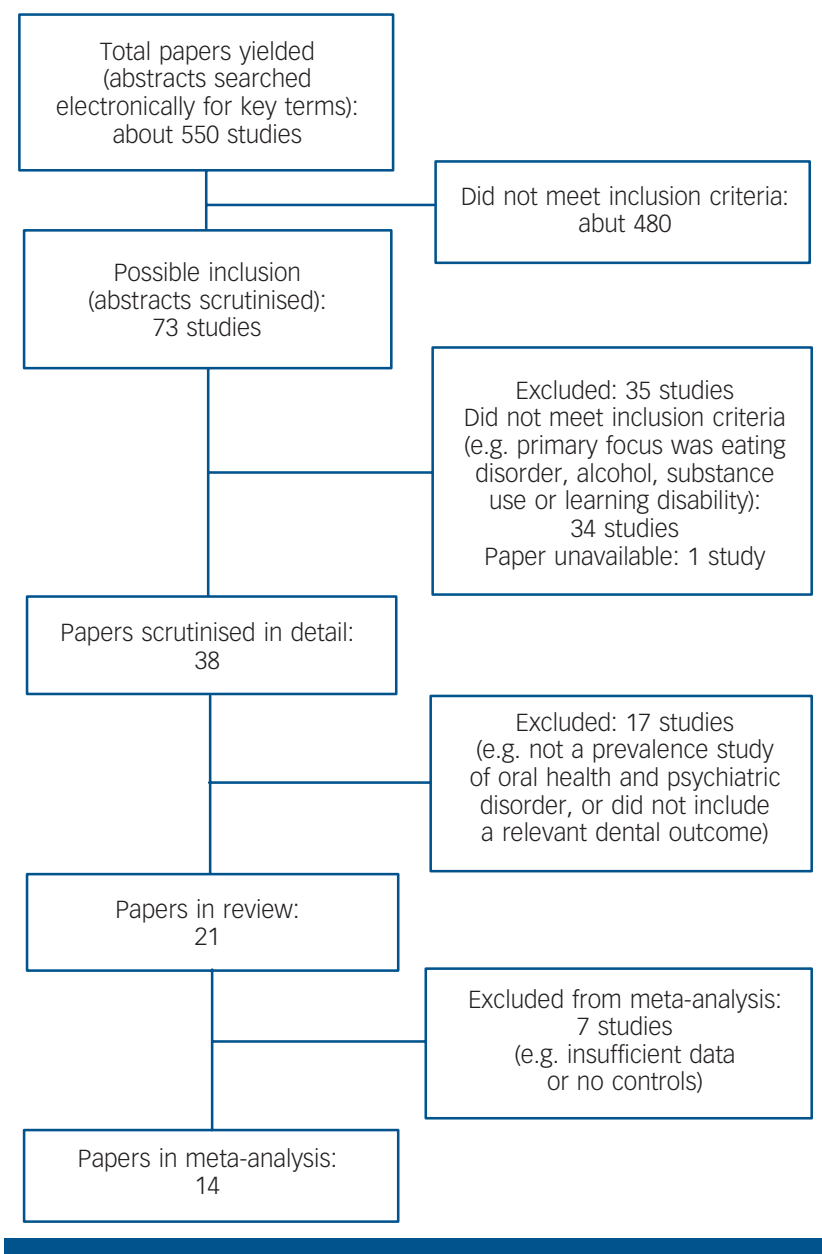

Fig. 1 Papers yielded by search strategy in systematic review. 
papers plus the abstract for which we were unable to obtain the full paper (22 studies). ${ }^{44}$ Ten studies were from Europe; four were from India, three from Israel, two from Australia and one each from South Africa, Hong Kong and the USA. The most common diagnosis was psychosis, usually schizophrenia. Other diagnoses (in descending order of frequency) included dementia, bipolar affective disorder, mood disorder, anxiety and personality disorder. Only seven studies used ICD or DSM diagnostic criteria (Table DS1). Ages ranged from 15 to 96 years.

Fourteen studies provided usable data for meta-analysis ( $n=2784$ psychiatric patients). ${ }^{1,11,12,17,27-30,33-38}$ Of the patients studied, 1515 (54\%) were men and 1269 (46\%) women. Three studies had data on control groups; ${ }^{17,27,28}$ for the other eleven studies comparison data from community surveys were available for a similar age group ( $n=31084$ controls) and within 10 years of the study (online Table DS2). ${ }^{18-21,45-51}$ Data on gender were available for 30327 controls, with similar numbers of men $(n=15245)$ and women $(n=15082)$; the gender ratio $(50 \%)$ was thus close to that of the patient group.

\section{Edentulousness}

Data on the proportion of edentulous patients were available for 16 studies (Table DS1) and varied from $3 \%$ in an Indian community to about $65 \%$ in studies reported from the UK and from Denmark. We were able to include nine studies in the meta-analysis, although in the case of one study comparison data were only available for those over 35 years old. ${ }^{30}$ Psychiatric patients $(n=1622)$ had over three times the odds of having lost all their teeth (95\% CI 1.6-7.2) compared with controls $(n=22448)$ (Fig. 2). For one study there was a choice of two community surveys as a comparison; $;^{20,48}$ using one or the other made no difference to the results. Restricting studies to those of in-patients (six studies), a marker of psychiatric symptom severity, or those using diagnostic criteria (DSM-III) (two studies) made no difference to the results. We found significant heterogeneity with or without outlying studies and in all the sensitivity analyses.

\section{Dental caries}

Mean values of DMFT ranged from 30.0 in Britain to 0.9 in India. ${ }^{36,37}$ Average DMFT scores in countries with more Western lifestyles - Europe, the USA and Israel - were generally over 20. In contrast, scores from India and South Africa were under 8.
The DMFS scores showed a similar pattern, with the highest score from Italy (88.6) and the lowest (2.5) from India. ${ }^{31,36}$ The extent of tooth decay was generally greater for people requiring in-patient care as well as for those with chronic and more severe psychiatric symptoms (Table DS1). We were able to include only seven studies in our meta- analysis. Psychiatric patients had significantly higher DMFS (mean difference 14.6, 95\% CI 4.125.1) and DMFT scores (mean difference 6.2, 95\% CI 0.6-11.8). They also had significantly more decayed surfaces and filled teeth, but not missing teeth (Fig. 3). The results for decayed surfaces and teeth were the only ones not to show significant heterogeneity (Fig. 3).

\section{Effect of fluoridation}

When we restricted the meta-analysis to studies from areas where fluoride was present in the water supply, ${ }^{12,34-36,38}$ the results for edentulousness (OR $=2.0,95 \%$ CI 0.6 to 6.0$)$ and DMFT (mean difference $6.6,95 \%$ CI -3.7 to 12.9 ) were no longer significant. However, these meta-analyses were based on only three and two studies respectively.

\section{Publication bias}

We were able to test for publication bias only for our primary outcome of edentulousness as there were insufficient studies for the other outcomes. The fail-safe $N$ of additional 'null' studies needed to reduce the overall odds ratio to non-significance was 103. Tests for funnel plot asymmetry gave a $P$-value of 0.8 . These results suggest that the findings for edentulousness were reasonably robust against publication bias.

\section{Discussion}

It is well known that individuals with severe mental illness have high rates of physical ill-health, including diabetes, cardiovascular disease, chronic lung disease and cancer. ${ }^{52}$ This in turn is associated with increased mortality from preventable physical disease, so that people with schizophrenia die 15-20 years earlier than the general population. Although the oral health of the general population has improved in much of the world, psychiatric patients remain at a disadvantage in a wide range of countries. This mirrors findings in other areas such as cardiovascular disease, where the health of the general population has

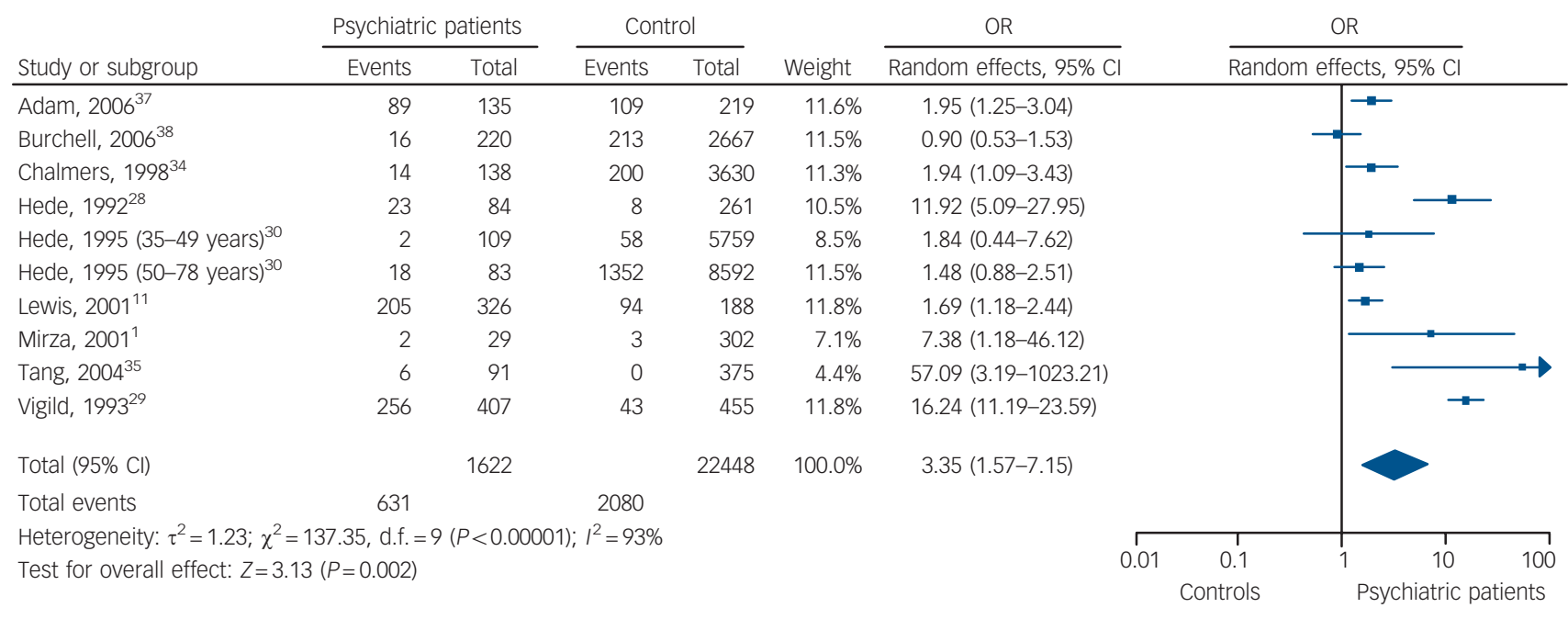

Fig. 2 Edentulousness. 


\begin{tabular}{|c|c|c|c|c|c|c|c|c|c|c|}
\hline \multirow[b]{2}{*}{ Study or subgroup } & \multicolumn{3}{|c|}{ Psychiatric patients } & \multicolumn{3}{|c|}{ Control } & \multirow[b]{2}{*}{ Weight } & \multirow{2}{*}{$\frac{\text { Mean difference }}{\text { Random effects, } 95 \% \mathrm{Cl}}$} & \multicolumn{2}{|c|}{ Mean difference } \\
\hline & Mean & s.d. & Total & Mean & s.d. & Total & & & Random e & ffects, $95 \% \mathrm{Cl}$ \\
\hline \multicolumn{11}{|l|}{ Decayed surfaces } \\
\hline Hede, 1995 (35-49 years) ${ }^{30}$ & 3.1 & 11.6 & 109 & 0.9 & 0.1 & 762 & $34.5 \%$ & 2.20 (0.02 to 4.38$)$ & & 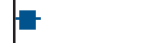 \\
\hline Hede, $1995\left(65-78\right.$ years) ${ }^{30}$ & 5.9 & 8.3 & 23 & 1.5 & 0.3 & 353 & $31.4 \%$ & 4.40 (1.01 to 7.79$)$ & & - \\
\hline Stoefe; $1990^{27}$ & 6.4 & 6.67 & 37 & 2.07 & 2.53 & 29 & $34.1 \%$ & 4.33 (1.99 to 6.67$)$ & & 단 \\
\hline Subtotal $(95 \% \mathrm{Cl})$ & & & 169 & & & 1144 & $100.0 \%$ & $3.42(1.93$ to 4.91$)$ & & $\checkmark$ \\
\hline \multicolumn{11}{|c|}{$\begin{array}{l}\text { Heterogeneity: } \tau^{2}=0.09 ; \chi^{2}=2.11, \text { d.f. }=2(P=0.35) ; I^{2}=5 \% \\
\text { Test for overall effect: } Z=4.51(P<0.00001)\end{array}$} \\
\hline \multicolumn{11}{|l|}{ DMFS } \\
\hline Hede, 1995 (35-49 years) ${ }^{30}$ & 68.3 & 33.3 & 109 & 46.6 & 0.7 & 762 & $46.3 \%$ & 21.70 (15.45 to 27.95$)$ & & - \\
\hline Hede, $1995\left(65-78\right.$ years) ${ }^{30}$ & 120.2 & 27.8 & 23 & 104.1 & 1.7 & 353 & $24.9 \%$ & 16.10 (4.74 to 27.46$)$ & & \\
\hline Stiefel, $1990^{27}$ & 31.9 & 22 & 37 & 27.4 & 20 & 29 & $28.7 \%$ & $4.50(-5.66$ to 14.66$)$ & & \\
\hline Subtotal $(95 \% \mathrm{Cl})$ & & & 169 & & & 1144 & $100.0 \%$ & 14.60 (4.05 to 25.14$)$ & & \\
\hline \multicolumn{11}{|c|}{$\begin{array}{l}\text { Heterogeneity: } \tau^{2}=64.52 ; \chi^{2}=8.00, \text { d.f. }=2(P=0.02) ; I^{2}=75 \% \\
\text { Test for overall effect: } Z=2.71(P=0.007)\end{array}$} \\
\hline \multicolumn{11}{|l|}{ Decayed teeth } \\
\hline Ramon, 2003 (18-34 years) $)^{12}$ & 9.16 & 5.2 & 54 & 2.55 & 3.12 & 7139 & $49.4 \%$ & 6.61 (5.22 to 8.00 ) & & \\
\hline Velasco, $1997^{33}$ & 7.95 & 6.86 & 565 & 2.9 & 2.9 & 261 & $50.6 \%$ & 5.05 (4.38 to 5.72 ) & & \\
\hline Subtotal $(95 \% \mathrm{Cl})$ & & & 619 & & & 7400 & $100.0 \%$ & 5.71 (4.20 to 7.22$)$ & & $\nabla$ \\
\hline \multicolumn{11}{|c|}{ Heterogeneity: $\tau^{2}=0.91 ; \chi^{2}=3.94$, d.f. $=1(P=0.05) ; I^{2}=75 \%$} \\
\hline \multicolumn{11}{|l|}{ Missing teeth } \\
\hline Ramon, 2003 (18-34 years) $)^{12}$ & 5.42 & 6.25 & 54 & 0.25 & 0.69 & 7139 & $32.7 \%$ & 5.17 (3.50 to 6.84) & & - \\
\hline Stiefel, $1990^{27}$ & 0.57 & 1.3 & 37 & 0.55 & 1.53 & 29 & $33.9 \%$ & $0.02(-0.68$ to 0.72$)$ & & 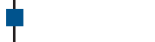 \\
\hline Velesco, $1997^{33}$ & 17.02 & 10.32 & 565 & 7.5 & 6.8 & 261 & $33.4 \%$ & $9.52(8.33$ to 10.71$)$ & & \\
\hline Subtotal $(95 \% \mathrm{Cl})$ & & & 656 & & & 7429 & $100.0 \%$ & $4.89(-1.50$ to 11.28$)$ & & \\
\hline \multicolumn{11}{|c|}{$\begin{array}{l}\text { Heterogeneity: } \tau^{2}=31.50 ; \chi^{2}=192.40, \text { d.f. }=2(P<0.00001) ; I^{2}=99 \% \\
\text { Test for overall effect: } Z=1.50(P=0.13)\end{array}$} \\
\hline \multicolumn{11}{|l|}{ DMFT } \\
\hline Kumar, $2006^{36}$ & 0.92 & 1.8 & 180 & 0.4 & 0.92 & 121 & $25.6 \%$ & 0.52 (0.21 to 0.83$)$ & & 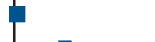 \\
\hline Ramon, 2003 (18-34 years) ${ }^{12}$ & 17.5 & 8.2 & 54 & 8.49 & 4.95 & 7139 & $23.9 \%$ & $9.01(6.82$ to 11.20$)$ & & \\
\hline Rekha, $2002^{17}$ & 6.1 & 6.87 & 326 & 3.2 & 3.49 & 156 & $25.3 \%$ & 2.90 (1.97 to 3.83$)$ & & E \\
\hline Velasco, $1997^{23}$ & 24.99 & 7.71 & 565 & 12.5 & 7.1 & 261 & $25.2 \%$ & $12.49(11.42$ to 13.56$)$ & & - \\
\hline Subtotal $(95 \% \mathrm{Cl})$ & & & 1125 & & & 7677 & $100.0 \%$ & 6.20 (0.56 to 11.83$)$ & & \\
\hline \multicolumn{11}{|c|}{$\begin{array}{l}\text { Heterogeneity: } \tau^{2}=36.62 ; \chi^{2}=495.19, \text { d.f. }=3(P<0.00001) ; I^{2}=99 \% \\
\text { Test for overall effect: } Z=2.16(P=0.03)\end{array}$} \\
\hline
\end{tabular}

Fig. 3 Dental caries (DFMS/DFMT, decayed, filled and missing surfaces/teeth).

improved but not that of people with severe mental illness. ${ }^{53}$ The results for our primary outcome, edentulousness, were particularly striking. The findings for DMFS and DMFT scores were less striking but still significant. This is possibly because both are more appropriate for dentate patients. It is impossible to record accurately the number of decayed or filled teeth if they have been lost through dental disease.

\section{Limitations}

There are a number of limitations to our study. There was considerable variation in outcome measures and how these were reported. Most studies had no comparison group and we were unable to find suitable community controls for many of the others. Although we were able to include nine studies $(n=1622)$ for the meta-analysis of our primary outcome (edentulousness), we had fewer studies for the other outcomes. Moreover, most studies did not use diagnostic criteria for the psychiatric disorders of interest. In addition, although we took into account age, secular trends in oral health and water fluoride levels in our choice of controls, we were unable to take into account other factors such as economic status or education level. It is unlikely that gender would have confounded our results. The gender distributions for both psychiatric patients and controls were similar (54\% v. 50\% male). In addition, community surveys indicate that edentulousness and tooth decay do not vary greatly between men and women, especially in younger populations. ${ }^{51,54}$ Where differences have been reported, women have worse dental disease than men; ${ }^{19,45,48,51}$ any effect on our results would therefore have been to underestimate the difference, given that there were $4 \%$ more men in the psychiatric sample than in the controls.

Many of our results showed heterogeneity. Where possible, we explored this further using sensitivity analyses of the effects of excluding outlying studies. ${ }^{25}$ In most cases heterogeneity could not be explained, either because there were too few studies for this to be an appropriate approach or because sensitivity analyses made no difference to the result. Accordingly, we used a random 
effects model throughout to incorporate heterogeneity into our analyses. ${ }^{25}$ In the absence of information to the contrary, this model assumes that differences between studies are random. However, although we have tried to minimise the effects of heterogeneity, our results should still be treated with caution.

\section{Explanations}

Explanations for these findings include poor oral hygiene resulting in plaque formation and gingivitis. As with other aspects of physical ill-health, alcohol and substance use, tobacco and diet (including the consumption of carbonated drinks) also contribute to poor oral health. For instance, edentulousness is associated with low fruit and vegetable intake in marginalised older adults even after adjusting for sociodemographic and behavioural variables. ${ }^{55}$ Smoking leads to an increased incidence of erosion, cervical abrasion and gingival necrosis, and other mucosal lesions are reported in people using oral cocaine. ${ }^{56}$ Psychotropic medications can also contribute to dental disease as many cause dry mouth (xerostomia) through reduced salivary flow. ${ }^{15,57}$ Relevant medications include conventional and atypical antipsychotics, all classes of antidepressants, and mood stabilisers. ${ }^{58}$ Xerostomia has been found to decrease overall quality of life, ${ }^{59}$ increase plaque and calculus formation, ${ }^{15}$ and lead to a higher incidence of caries, gingivitis and periodontitis. ${ }^{12,15,57}$

People with severe mental illness may also have priorities other than their oral health, or lack privacy for oral hygiene owing to poor housing or homelessness. These issues are compounded by difficulties with access to dental care. People with severe mental illness may be reluctant to seek treatment because of the fear of pain or dental phobia, possibly exacerbated by the cost of dental care. Even in Australia and the UK, universal healthcare does not comprehensively cover dental treatment. It is possible that the gap in oral health for people with severe mental illness may be worsening with the move to care in the community. Many long-stay psychiatric hospitals used to have visiting dental professionals, and it is interesting that the need for dental care was lower in the one study of patients on long-stay psychiatric wards, ${ }^{11,60}$ which was described as having such a dental service. ${ }^{60}$ On the other hand, the need for dental care was high in three other studies of patients on long-stay wards where the presence of such a service was unclear. ${ }^{12,31,33}$ Another explanation for these discrepant findings might be different levels of edentulousness reported in these studies, ranging from $62 \%$ in the study by Lewis et al to around $10 \% .^{11,31,33}$ With severe tooth loss, some measures of caries such as the number of decayed teeth actually fall. To this must be added the effects of societal and cultural differences between countries. Further research is needed to clarify how all these factors contribute to differences in findings between studies.

In terms of protective factors, the presence of fluoride in the water supply should benefit all sectors of the population including those with severe mental illness. Restricting our meta-analyses to studies where fluoride was present did indicate that the difference in edentulousness and DMFT scores between the general population and those with severe mental illness was no longer significant. However, this finding should be interpreted with caution because these meta-analyses were based on only two studies and could be subject to type 2 error. In addition, we could not assess for the use of fluoride supplements such as in tablets, table salt, milk or toothpastes.

\section{Implications}

For clinicians, consideration of oral health should be part of a comprehensive assessment of patients with severe mental illness. In a UK survey, the vast majority of patients reported that staff on the ward or their professional caregivers in the community had never asked them about any dental problems. ${ }^{1}$ Nursing care plans on admission to hospital should include the recording of factors known to cause oral ill-health such as psychotropic medication and tobacco or substance use, as well as a basic assessment of oral hygiene. Brief assessment tools are available that can be completed by people who are not dentally trained. ${ }^{61}$ Nursing care plans could also include the supply of toothbrushes and denture baths, as well as instruction in their use. A study in Missouri has demonstrated the efficacy of such programmes, at least in terms of short-term improvements in oral hygiene. ${ }^{62}$

For patients in the community, case management should include attention to oral hygiene and health including advice on diet, smoking and brushing technique. The basic messages for oral health promotion and disease prevention should include the following: brushing twice a day with a fluoridated toothpaste; avoidance of sugars in foods or carbonated drinks; healthy eating habits; smoking cessation; and keeping alcohol consumption to a minimum. Saliva substitutes can help with dry mouth secondary to psychotropic medication. Finally, case managers should encourage patients to have regular dental check-ups and be prepared to address dental anxiety and phobia, if present. Policy makers should consider providing free, accessible dental care for people with severe mental illness. Examples include the 'Dental as Anything' programme in Melbourne, which offers a collaborative outreach dental service and follow-up treatment to people with severe mental illness. ${ }^{38}$ Elsewhere in Australia, Queensland's strategy to improve the physical health of people with severe mental illness (Activate: Mind and Body) includes the promotion of oral hygiene and regular care from a dentist. ${ }^{63}$

Although this needs to be confirmed by further research, our findings suggest that there is less of a gap in oral health between people with severe mental illness and the general population where fluoride is present in the water supply. The debate on fluoridation should therefore consider how this might help disadvantaged groups such as people with severe mental illness. Further research should include well-designed studies of sufficient power and with age-matched controls. Given the diversity of findings across countries and the possible effect of fluoride, diet and societal norms, a multicentre study would be especially appropriate. One hundred people with severe mental illness, with the same number of controls, would be required at each site to have an $80 \%$ chance of detecting the difference in edentulousness we have reported at the $95 \%$ confidence level. Such a study could describe how oral health problems in people with psychiatric illness varied by age, gender, type and severity of illness. The inclusion of appropriate controls would better establish the relative contributions of lifestyle, psychotropic medication, psychiatric symptoms, poverty and accessibility to dental care in analysing oral health outcomes. Answers to these questions would enable better targeting of services in the future. The role of protective factors such as fluoridation in mitigating disparities should also be explored.

Steve Kisely, MD, PhD, FRCPsych, FRANZCP, FAFPHM, FFPH, Health LinQ, University
of Queensland, and Griffith Health Institute, Griffith University, Queensland; Lake-Hui
Quek, PhD, Joanne Pais, MS, Health LinQ, University of Queensland; Ratilal Lalloo,
MChD, PhD, School of Dentistry and Oral Health, Griffith University and Griffith Health
Institute, Queensland; Newell W. Johnson, MDSC, PhD, FDSRCS, PRCPath, FMedSCi,
Griffith Health Institute, Griffith University, Queensland; David Lawrence, PhD,
Centre for Developmental Health, Curtin University of Technology and Telethon
Institute for Child Health Research, Perth, Western Australia, Australia

Correspondence: Professor Steve Kisely, Health LinQ, Room 518(A), MacGregor Building (No. 64), University of Queensland, St Lucia, Brisbane, Qld 4072, Australia. Email: s.kisely@uq.edu.au

First received 22 April 2010, final revision 20 Oct 2011, accepted 17 Feb 2011 


\section{References}

1 Mirza I, Day R, Wulff-Cochrane V, Phelan M. Oral health of psychiatric in-patients. A point prevalence survey of an inner-city hospital. Psychiatr Bull 2001; 25: 143-5

2 Cullinan MP, Ford PJ, Seymour GJ. Periodontal disease and systemic health: current status. Aust Dent J 2009; 54 (suppl 1): S62-9.

3 Chapple IL. The impact of oral disease upon systemic health - symposium overview. J Dent 2009; 37: S568-71.

4 Haumschild MS, Haumschild RJ. The importance of oral health in long-term care. J Am Med Dir Assoc 2009; 10: 667-71.

5 Williams RC, Barnett AH, Claffey N, Davis M, Gadsby R, Kellett M, et al. The potential impact of periodontal disease on general health: a consensus view. Curr Med Res Opin 2008; 24: 1635-43.

6 Humphrey LL, Fu R, Buckley DI, Freeman M, Helfand M. Periodontal disease and coronary heart disease incidence: a systematic review and meta-analysis. J Gen Intern Med 2008; 23: 2079-86.

7 Desvarieux M, Demmer RT, Rundek T, Boden-Albala B, Jacobs DR, Papapanou PN, et al. Relationship between periodontal disease, tooth loss, and carotid artery plaque: the Oral Infections and Vascular Disease Epidemiology Study (INVEST). Stroke 2003; 34: 2120-5.

8 Shultis WA, Weil EJ, Looker HC, Curtis JM, Shlossman M, Genco RJ, et al. Effect of periodontitis on overt nephropathy and end-stage renal disease in type 2 diabetes. Diabetes Care 2007; 30: 306-11.

9 Azarpazhooh A, Leake JL. Systematic review of the association between respiratory diseases and oral health. J Periodontol 2006; 77: 1465-82.

10 Bardow A, Nyvad B, Nauntofte B. Relationships between medication intake complaints of dry mouth, salivary flow rate and composition, and the rate of tooth demineralization in situ. Arch Oral Biol 2001; 46: 413-23.

11 Lewis S, Jagger RG, Treasure E. The oral health of psychiatric in-patients in South Wales. Spec Care Dentist 2001; 21: 182-6.

12 Ramon T, Grinshpoon A, Zusman SP, Weizman A. Oral health and treatment needs of institutionalized chronic psychiatric patients in Israel. Eur Psychiatry 2003; 18: 101-5.

13 Selwitz RH, Ismail Al, Pitts NB. Dental caries. Lancet 2007; 369: 51-9.

14 Pihlstrom BL, Michalowicz BS, Johnson NW. Periodontal diseases. Lancet 2005; 366: 1809-20.

15 Cormac I, Jenkins P. Understanding the importance of oral health in psychiatric patients. Adv Psychiatr Treat 1999; 5: 53-60.

16 Roberts-Thomson K, Do L. Oral health status. In Australia's Dental Generations: The National Survey of Adult Oral Health 2004-06 (eds GD Slade, AJ Spencer, KF Roberts-Thomson): 81-137. Cat. no. DEN 165. Dental Statistics and Research Series no. 34. Australian Institute of Health and Welfare, 2007.

17 Rekha R, Hiremath SS, Bharath S. Oral health status and treatment requirements of hospitalized psychiatric patients in Bangalore city: a comparative study. J Indian Soc Pedod Prev Dent 2002; 20: 63-7.

18 Mandal KP, Tewari AB, Chawla HS, Gauba KD. Prevalence and severity of dental caries and treatment needs among population in the Eastern states of India. J Indian Soc Pedod Prev Dent 2001; 19: 85-91.

19 AlHW Dental Statistics and Research Unit. The National Survey of Adult Oral Health 2004-06: Victoria. Cat. no. DEN 181. Dental Statistics and Research Series no. 45. Australian Institute of Health and Welfare, 2008

20 Petersen $\mathrm{PE}$, Kjoller M, Christensen LB, Krustrup U. Changing dentate status of adults, use of dental health services, and achievement of national dental health goals in Denmark by the year 2000. J Public Health Dent 2004; 64: 127-35.

21 Kelly M, Steele J, Nuttall N, Bradnock G, Morris J, Nunn J, et al. Adult Dental Health Survey: Oral Health in the United Kingdom 1998. TSO (The Stationery Office), 2000 .

22 Marthaler TM, O'Mullane DM, Vrbic V. The prevalence of dental caries in Europe 1990-1995. ORCA Saturday afternoon symposium 1995. Caries Res 1996; 30: 237-55.

23 American Dental Association/Centers for Disease Control and Prevention. Water Fluoridation: Nature's Way to Prevent Tooth Decay. ADA/CDC, 2006 (http://www.cdc.gov/fluoridation/pdf/natures_way.pdf).

24 Stillman-Lowe C (ed). One in a Million: The Facts About Water Fluoridation. British Fluoridation Society, UK Public Health Association, British Dental Association and Faculty of Public Health, 2004.

25 Higgins JPT, Green S (eds). Cochrane Handbook for Systematic Reviews of Interventions Version 5.0.2. Cochrane Collaboration, 2009 (http:// www.cochrane-handbook.org).

26 Higgins JP, Thompson SG, Deeks JJ, Altman DG. Measuring inconsistency in meta-analyses. BMJ 2003; 327: 557-60.
27 Stiefel DJ, Truelove EL, Menard TW, Anderson VK, Doyle PE, Mandel LS. A comparison of the oral health of persons with and without chronic mental illness in community settings. Spec Care Dentist 1990; 10: 6-12.

28 Hede B, Peterson PE. Self-assessment of dental health among Danish noninstitutionalized psychiatric patients. Spec Care Dentist 1992; 12: 33-6.

29 Vigild M, Brinck JJ, Christensen J. Oral health and treatment needs among patients in psychiatric institutions for the elderly. Community Dent Oral Epidemiol 1993; 21: 169-71.

30 Hede B. Oral health in Danish hospitalized psychiatric patients. Community Dent Oral Epidemiol 1995; 23: 44-8.

31 Angelillo IF, Nobile CG, Pavia M, De Fazio P, Puca M, Amati A. Dental health and treatment needs in institutionalized psychiatric patients in Italy. Community Dent Oral Epidemiol 1995; 23: 360-4

32 Thomas A, Lavrentzou E, Karouzos C, Kontis C. Factors which influence the oral condition of chronic schizophrenia patients. Spec Care Dentist 1996; 16: 84-6.

33 Velasco E, Machuca G, Martinez-Sahuquillo A, Rios V, Lacalle J, Bullon P. Dental health among institutionalized psychiatric patients in Spain. Spec Care Dentist 1997; 17: 203-6.

34 Chalmers JM, Smith KD, Carter K. A multidisciplinary dental program for community-living adults with chronic mental illness. Spec Care Dentist 1998; 18: 194-201.

35 Tang WK, Sun FC, Ungvari GS, O'Donnell D. Oral health of psychiatric in-patients in Hong Kong. Int J Soc Psychiatry 2004; 50: 186-91.

36 Kumar M, Chandu GN, Shafiulla MD. Oral health status and treatment needs in institutionalized psychiatric patients: one year descriptive cross sectional study. Indian J Dent Res 2006; 17: 171-7.

37 Adam $\mathrm{H}$, Preston AJ. The oral health of individuals with dementia in nursing homes. Gerodontology 2006; 23: 99-105.

38 Burchell A, Fembacher S, Lewis R, Neil A. 'Dental as anything': inner south community health service dental outreach to people with a mental illness. Austr J Primary Health 2006; 12: 75-82.

39 Bhansali S, Tripathi A, Tiwari SC, Singh SV. A study of the prosthodontic and oral health needs of an ageing psychiatric population. Gerodontology 2008; 25: 113-7.

40 Persson K, Axtelius B, Soderfeldt B, Ostman M. Monitoring oral health and dental attendance in an outpatient psychiatric population. J Psychiatr Ment Health Nurs 2009; 16: 263-71.

41 Ponizovsky AM, Zusman SP, Dekel D, Masarwa AE, Ramon T, Natapov L, et al. Effect of implementing dental services in Israeli psychiatric hospitals on the oral and dental health of inpatients. Psychiatr Serv 2009; 60: 799-803.

42 Rudolph MJ, Chikte UM. Dental caries experience and peridontal disease in institutionalised male psychiatric patients. J Dent Assoc S Africa 1993; 48: 451-4.

43 Zusman SP, Ponizovsky AM, Dekel D, Masarwa AE, Ramon T, Natapov L, et al. An assessment of the dental health of chronic institutionalized patients with psychiatric disease in Israel. Spec Care Dentist 2010; 30 18-22.

44 Kenkre AM, Spadigam AE. Oral health and treatment needs in institutionalized psychiatric patients in India. Indian J Dent Res 2000; 11: $5-11$.

45 AlHW Dental Statistics and Research Unit. The National Survey of Adult Oral Health 2004-06: New South Wales. Cat. no. DEN 176. Dental Statistics and Research Series no. 40. Australian Institute of Health and Welfare, 2008.

46 Kirkegaard E, Borgnakke WS, Gronbrek L. Oral health status, dental treatment need, and dental care habits in a representative sample of the adult Danish population. Royal Dental College, 1986.

47 Oral Health Education Unit. 2001 Oral Health Survey. Department of Health of the Government of the Hong Kong Special Administrative Region, 2006 (http://www.toothclub.gov.hk/en/en_home_06_01.htm).

48 Palmqvist S, Soderfeldt B, Vigild M, Kihl J. Dental conditions in middle-aged and older people in Denmark and Sweden: a comparative study of the influence of socioeconomic and attitudinal factors. Acta Odontol Scand 2000; 58: $113-8$.

49 Sgan-Cohen HD, Katz J, Horev T, Dinte A, Eldad A. Trends in caries and associated variables among young Israeli adults over 5 decades. Community Dent Oral Epidemiol 2000; 28: 234-40.

50 Alvarez-Arenal A, Alvarez-Riesgo JA, Petia Lopez JM, Fernandez Vazquez IP, Villa Vigil MA. DMFT and treatment needs in adult population of Oviedo, Spain. Community Dent Oral Epidemiol 1996; 24: 17-20.

51 Krustrup U, Petersen PE. Dental caries prevalence among adults in Denmark - the impact of socio-demographic factors and use of oral health services. Community Dent Health 2007; 24: 225-32. 
52 Lawrence D, Jablensky AV, Holman CD, Pinder TJ. Mortality in Western Australian psychiatric patients. Soc Psychiatry Psychiatr Epidemiol 2000; 35: $341-7$

53 Lawrence DM, Holman CDJ, Jablensky AV, Hobbs MST. Death rate from ischaemic heart disease in Western Australian psychiatric patients 1980-1998. Br J Psychiatry 2003; 182: 31-6.

54 Office for National Statistics. Adult Dental Health Survey. Oral Health in the United Kingdom 1998: 1-12. TSO (The Stationery Office), 2000.

55 Tsakos G, Herrick K, Sheiham A, Watt RG. Edentulism and fruit and vegetable intake in low-income adults. J Dent Res 2010; 89: 462-7.

56 Krutchkoff DJ, Eisenberg E, O'Brien JE, Ponzillo JJ. Cocaine-induced dental erosions. N Engl J Med 1990; 322: 408.

57 Sjogren R, Nordstrom G. Oral health status of psychiatric patients. J Clin Nurs 2000; 9: 632-8.

58 Sreebny LM, Schwartz SS. A reference guide to drugs and dry mouth 2nd edition. Gerodontology 1997; 14: 33-47.
59 Thomson WM, Lawrence HP, Broadbent JM, Poulton R. The impact of xerostomia on oral-health-related quality of life among younger adults. Health Qual Life Outcomes 2006; 4: 86.

60 Barnes GP, Allen EH, Parker WA, Lyon TC, Armentrout W, Cole JS. Dental treatment needs among hospitalized adult mental patients. Spec Care Dentist 1988; 8: 173-7.

61 Australian Research Centre for Population Oral Health, The University of Adelaide. Oral Health Promotion Clearinghouse (https:// www.adelaide.edu.au/oral-health-promotion/).

62 Almomani $\mathrm{F}$, Brown $\mathrm{C}$, Williams KB. The effect of an oral health promotion program for people with psychiatric disabilities. Psychiatr Rehabil J 2006; 29 274-81.

63 General Practice Queensland. Activate: Mind and Body. General Practice Queensland, 2009 (http://www.gpqld.com.au/page/Programs/Mental_Health/ Improving_the_Physical_Health_of_People_with_a_Severe_Mental_Illness_ Project/).

\section{4:48 Psychosis}

\section{Sarah Kane}

A room of expressionless faces staring blankly at my pain, so devoid of meaning there must be evil intent.

Dr This and Dr That and Dr Whatsit who's just passing and thought he'd pop in to take the piss as well. Burning in a hot tunnel of dismay, my humiliation complete as I shake without reason and stumble over words and have nothing to say about my 'illness' which anyway amounts only to knowing that there's no point in anything because I'm going to die. And I am deadlocked by that smooth psychiatric voice of reason which tells me there is an objective reality in which my body and mind are one. But I am not here and never have been. Dr This writes it down and Dr That attempts a sympathetic murmur. Watching me, judging me, smelling the crippling failure oozing from my skin, my desperation clawing and all-consuming panic drenching me as I gape in horror at the world and wonder why everyone is smiling and looking at me with secret knowledge of my aching shame.

Shame shame shame.

Drown in your fucking shame.

Inscrutable doctors, sensible doctors, way-out doctors, doctors you'd think were fucking patients if you weren't shown proof otherwise, ask the same questions, put words in my mouth, offer chemical cures for congenital anguish and cover each other's arses until I want to scream for you, the only doctor who ever touched me voluntarily, who looked me in the eye, who laughed at my gallows humour spoken in the voice from the newly-dug grave, who took the piss when I shaved my head, who lied and said it was nice to see me. Who lied. And said it was nice to see me.

4:48 Psychosis (p. 209), Methuen Publishing, 2001. We published another excerpt from Psychosis in the August 2011 issue of the Journal.

Chosen by Femi Oyebode. 